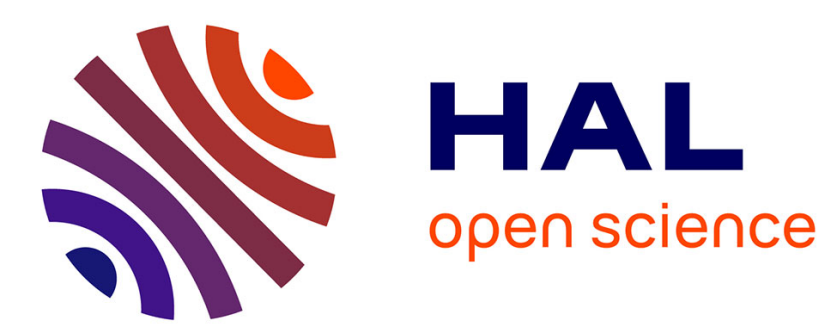

\title{
Nanojunction between fullerene and one-dimensional conductive polymer on solid surfaces
}

Masato Nakaya, Yuji Okawa, Christian Joachim, Masakazu Aono, Tomonobu Nakayama

\section{- To cite this version:}

Masato Nakaya, Yuji Okawa, Christian Joachim, Masakazu Aono, Tomonobu Nakayama. Nanojunction between fullerene and one-dimensional conductive polymer on solid surfaces. ACS Nano, 2014, 8 (12), pp.12259-12264. 10.1021/nn504275b . hal-01712778

\section{HAL Id: hal-01712778 https://hal.science/hal-01712778}

Submitted on 18 May 2018

HAL is a multi-disciplinary open access archive for the deposit and dissemination of scientific research documents, whether they are published or not. The documents may come from teaching and research institutions in France or abroad, or from public or private research centers.
L'archive ouverte pluridisciplinaire HAL, est destinée au dépôt et à la diffusion de documents scientifiques de niveau recherche, publiés ou non, émanant des établissements d'enseignement et de recherche français ou étrangers, des laboratoires publics ou privés. 


\title{
Nanojunction between Fullerene and One-Dimensional Conductive Polymer on solid surfaces
}

\author{
Masato Nakaya,${ }^{\dagger}$ Yuji Okawa, ${ }^{\dagger}$ Christian Joachim,,${ }^{\dagger} \pitchfork$ Masakazu Aono,${ }^{\dagger}$ \\ Tomonobu Nakayama \\ $\dagger$ International Center for Materials Nanoarchitectonics (MANA), National Institute for Materials \\ Science (NIMS), 1-1 Namiki, Tsukuba, Ibaraki 305-0044, Japan
}

†Centre d'Elaboration des Matériaux et d'études structurales (CEMES), Centre National de la

Recherche Scientifique (CNRS), 29 rue J. Marvig, 31055 Toulouse Cedex, France

$\S$ Graduate School of Pure and Applied Sciences, University of Tsukuba

1-1 Namiki, Tsukuba, Ibaraki 305-0044, Japan

*Address correspondence to

Tel: +81-29-860-4129

Fax: +81-29-860-4886

E-mail: NAKAYAMA.Tomonobu@ nims.go.jp 


\section{ABSTRACT}

Bottom-up creation of huge molecular complexes by covalently interconnecting among functional molecules and conductive polymers is a key technology toward constructing nanoscale electronic circuits. Here, we have created an array of the molecules-polymer nanojunction from $\mathrm{C}_{60}$ molecules and polydiacetylene (PDA) nanowires at the designated position on solid surfaces by controlling self-assemblies and intermolecular chemical reactions of molecular ingredients predeposited onto the surfaces. In the proposed method, construction of each nanojunction spontaneously proceeds via two types of chemical reactions; a chain polymerization among self-assembled diacetylene compound molecules for creating a single PDA nanowire and a following cycloaddition reaction between a propagating forefront part of the PDA backbone and a single $\mathrm{C}_{60}$ molecule adsorbed or diffusing on the surface. Scanning tunneling microscopy has proved that the $\mathrm{C}_{60}$ molecule is covalently connected with an each edge of $\pi$-conjugated PDA backbone. Furthermore, it has been also found reduction of the energy gap of the $\mathrm{C}_{60}$ molecule in nanojunctions compared with that of pristine $\mathrm{C}_{60}$ molecules, which is considered to come from the covalent interaction between the PDA edge and the $\mathrm{C}_{60}$ molecule.

\section{KEYWORDS}

Fullerene, polymer, STM, molecular electronics, heterojunction 
Construction of electronics from only molecule-based components is one of the ultimate goals in the recent molecular science and technology. ${ }^{1-4}$ Since the individual organic molecules behave as the unit element exhibiting peculiar physicochemical properties, creation of nanoscale hetero-junctions by interconnecting two kinds of organic molecules in the combination of donor-acceptor, host-guest and so on, offers molecular scale active elements of nanodevices exhibiting sophisticated functions such as an electrical rectification, ${ }^{5}$ switching,${ }^{6-8}$ photoelectric conversion, ${ }^{9}$ and logical operation. ${ }^{10}$ Particularly, toward realizing the molecular circuitry, ${ }^{11}$ creating an array of the nanojunctions between the one-dimensional (1D) conductive polymers and functional molecules is attractive, in which the 1D polymer is expected to behave not only as a wire but also as a part of nanojunction. ${ }^{12,13}$ An essential requirement in this concept is to connect the functional molecules with the $1 \mathrm{D}$ polymer via covalent bonds, which realizes well-defined physical and/or electrical contact in the nanojunction and improves its performances such as the structural stability and/or efficiency of charged-carrier transfers. Although such the molecule-polymer system would be finely created by advanced chemical synthesis in liquid-phase, it is essentially difficult to arrange such the huge molecular assemblies on solid surfaces while remaining intact. In constant, it has been recently demonstrated that some of macromolecules such as polymers and huge molecular complexes can be synthesized on solid surfaces by controlling covalent assembly among molecular building blocks deposited onto the surfaces. ${ }^{12-18}$ This methodology also allows us to investigate pristine geometry and electronic properties with atomic 
resolution of such the macromolecule systems using scanning tunneling microscopy and spectroscopy (STM/STS). In this article, we have constructed an array of molecules-polymer nanojunction on solid surfaces from fullerene $\mathrm{C}_{60}$ molecule ${ }^{19}$ and 1D polymer nanowire of diacetylene (DA) compound molecules, polydiacetylene (PDA), ${ }^{12}$ in which $\mathrm{C}_{60}$ molecule is covalently bound with an edge of $\pi$-conjugated PDA moiety.

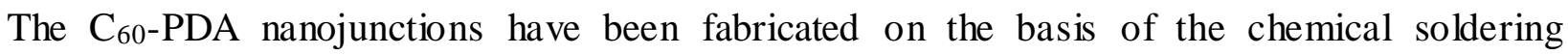
method. ${ }^{12,20}$ The key to this method is a linear chain polymerization in the self-assembled monolayer (SAM) of DA molecules, as shown in Figures 1B and C, which is induced via electronic excitation of DA molecules by electrons inelastically tunneling between an STM tip and substrates or by photons irradiated from ultraviolet (UV) light source. To briefly describing the important aspect of the chain polymerization, DA moiety in a monomer molecule is firstly excited as a reactive diradical and then dimer is created by an addition reaction between the radical and neighboring DA molecule. Since the created dimer also has reactive terminals, 1D polymer is extended by spontaneously repeating the addition reactions along a molecular row of DA moieties in the SAM. ${ }^{12,20}$ Interestingly, propagating reactive terminal of the PDA reacts not only with a neighboring DA molecule but also with different molecular species adsorbed on the row of DA moieties. ${ }^{12,20}$ However, despite a simplicity, versatility, and potential ability of this method for creating an array of the polymer-molecule nanojunctions on solid surfaces, it has been demonstrated for only fabricating a nanojunction between PDA nanowire 
and a single phthalocyanine molecule. In the current study, we have shown that this method is also useful for covalently connecting the PDA nanowire with $\mathrm{C}_{60}$ molecule via cycloaddition reaction.

\section{RESULTS AND DISCUSSION}

Figure 2A shows STM image of clean surface of $\mathrm{MoS}_{2}$ taken after simultaneously depositing 1.0 and 0.1 ML of DA compound and $\mathrm{C}_{60}$ molecules, respectively, at room temperature (RT). In the current work, 10,12-pentacosadiynoic acid $\left[R-\mathrm{C} \equiv \mathrm{C}-\mathrm{C} \equiv \mathrm{C}-R^{\prime}\right.$, where $\mathrm{C} \equiv \mathrm{C}-\mathrm{C} \equiv \mathrm{C}, R$, and $R^{\prime}$ correspond to the DA moiety, $\mathrm{CH}_{3}\left(\mathrm{CH}_{2}\right)_{11}$, and $\left(\mathrm{CH}_{2}\right)_{8} \mathrm{COOH}$ side chains, respectively] were used as the DA compound molecule. The region A and B in Figure 2A correspond to a SAM and monolayer islands of DA and $\mathrm{C}_{60}$ molecules, respectively, as discussed below. It is noted that similar structures have been also prepared on clean surfaces of highly oriented pyrolytic graphite (HOPG). In the high-resolution image of the region A (Figure 2B), parallel bright lines separated by two kinds of distance of about $\sim 3.0$ and $\sim 4.0 \mathrm{~nm}$ are observed. In addition, an array of slightly bright spots along the bright lines with separation of $\approx 0.5 \mathrm{~nm}$ is also observed in Figure $2 \mathrm{~B}$. According to the previous STM studies on SAMs of the same DA compound molecules formed by Langmuir-Schaefer (LS) and drop casting methods, ${ }^{20-23}$ the DA SAM is composed of the molecules lying flat on substrate surface and aligning parallel to each other with intermolecular distance of $0.47 \mathrm{~nm}$, as shown in inset in Figure $2 \mathrm{~B}$. In these LS and drop-casting films, the aligned DA moieties are observed as bright lines with two types of 
spacing of 3.0 and $3.8 \mathrm{~nm}$ in STM observations, because DA molecules are arranged in a manner such that the $\mathrm{COOH}$ end-groups of the chain are opposite to those of a neighboring molecule. Observed periodicity in the region A agrees well with that of the LS and drop-casting films of DA molecules.

On the other hand, Figure 2C shows a high-resolution STM image taken at a boundary between the DA SAM and a $\mathrm{C}_{60}$ island with a single-molecule height. The $\mathrm{C}_{60}$ island is composed of hexagonally-ordered $\mathrm{C}_{60}$ molecules with intermolecular distance of $\approx 1.0 \mathrm{~nm}$. This ordering is similar to that in the multilayer films consist of closely-packed $\mathrm{C}_{60}$ molecules. ${ }^{24}$ The arrangement of $\mathrm{C}_{60}$ molecules is maintained during the lateral growth of the $\mathrm{C}_{60}$ islands by additional deposition of $\mathrm{C}_{60}$ molecules till the monolayer $\mathrm{C}_{60}$ film covering over the DA SAM (See Supporting Information), although there is a large lattice mismatch between the monolayer film of closely-packed $\mathrm{C}_{60}$ molecules and the DA SAM. This result is different from the cases of $\mathrm{C}_{60}$ adlayer formation on SAMs of cyclothiophenes, ${ }^{25} \alpha$-sexithiophenes, ${ }^{26}$ acridine-9-carboxylic acids, ${ }^{27}$ zinc porphyrin derivatives, ${ }^{28}$ and so on, on which the arrangement of $\mathrm{C}_{60}$ molecules is strongly modified by a donor-acceptor interaction between $\mathrm{C}_{60}$ molecules and the SAMs. It is also important to point out that, in our experiments, the DA and $\mathrm{C}_{60}$ molecules were simultaneously deposited at various rates onto the $\mathrm{MoS}_{2}$ and HOPG surfaces, molecular-scale mixtures ${ }^{29}$ of them have never been created on surfaces. The above experimental observations indicate that van des Waals interactions between $\mathrm{C}_{60}$ and DA molecules are much smaller than the ones in between the $\mathrm{C}_{60}$ molecules. This is consistent with another fact that the $\mathrm{C}_{60}$ molecules 
in the nano-island are observed as smooth sphere (Figure 2C), indicating that the each $\mathrm{C}_{60}$ molecule freely rotates on the DA SAM similar to those on the chemically inert surfaces. ${ }^{30}$

The $\mathrm{C}_{60}$ - DA van der Waals interactions is locally modified by inducing chain polymerizations between the DA molecules. In the following example, the chain polymerization was induced by irradiating UV light under ultrahigh-vacuum (UHV) using low-pressure mercury lamp ( 254 $\mathrm{nm}$ in wavelength and $\sim 1.3 \mathrm{~mW} / \mathrm{cm}^{2}$ in power density at the sample position) for $60 \mathrm{~min}$. Figure $3 \mathrm{~A}$ shows an STM image of a DA SAM and $\mathrm{C}_{60}$ islands after irradiating the UV light. An array of nanowires exhibiting the very bright image contrast correspond to backbones of PDA created by the chain polymerization between DA molecules, as discussed in the previous STM studies. ${ }^{12,20-23}$ The bright image contrast of the PDA backbone simultaneously originates from its geometrical lift-up by $0.15 \mathrm{~nm}$ (Figure 1D) and a closure of its HOMO-LUMO gap neat Fermi level $\left(E_{\mathrm{F}}\right)$ as compared with the DA monomers. ${ }^{12,20,31}$ Figure 3B shows the magnified image of the region surrounded by the blue line in Figure 3A, in which $\mathrm{C}_{60}$ molecules contacting with each edge of PDA nanowires (blue arrows) exhibit a bright image contrast. The correlation between change in the image contrast of $\mathrm{C}_{60}$ molecule and the formation of the PDA nanowire is clearly demonstrated by following experiments. Figures 3C and 3D show STM images of two $\mathrm{C}_{60}$ islands formed on a DA SAM, which were taken before and after STM-induced chain polymerization, respectively, triggered by applying sample bias voltage $\left(V_{\mathrm{s}}\right)$ of $-3.3 \mathrm{~V}$ for $1 \mathrm{~s}$ at each tip position indicated by crosses in Figure 3C. After these procedures, seven PDA 
nanowires have been created along an array of DA moieties and terminated by edges of $\mathrm{C}_{60}$ nano islands, as shown in Figure 3D. Upper and lower panels in Figure 3E show magnified images of the region surrounded by the blue line in Figure 3D taken before and after creating a single PDA nanowire, respectively. In comparison between them, it has been clearly observed that the single $\mathrm{C}_{60}$ molecule exhibits brighter image contrast by connecting with the PDA nanowire. This bright appearance is considered to mainly originate from a shift in energy of the C60 frontier molecular orbitals which is considered to occur by covalent bonding to the edge of PDA nanowire as discussed latter. A $\mathrm{C}_{60}$ molecule behaves as an anchor part for the physical and electronic contacts between the $\mathrm{C}_{60}$ island and a PDA nanowire.

Actually, we have gained experimental evidences that the $\mathrm{C}_{60}$ molecule is strongly bound to the edge of PDA nanowire. In the present study, $\mathrm{C}_{60}$ molecules deposited onto DA SAMs were not observed as isolated single molecule adsorbates but mostly as islands, as mentioned above. Also two-dimensional (2D) gas phase of $\mathrm{C}_{60}$ molecules are formed as the minor structure and recognized as noisy feature around $\mathrm{C}_{60}$ islands in STM images. Figure $4 \mathrm{~A}$ shows an STM image of the gas-phase $\mathrm{C}_{60}$ molecules around a $\mathrm{C}_{60}$ island, which taken after inducing the chain polymerization by UV light irradiation. Interestingly, we recognize that four $\mathrm{C}_{60}$ molecules are individually immobilized with each edge of four PDA nanowires in the vicinity of the 2D gas as indicated by blue dotted circles. Furthermore, the $\mathrm{C}_{60}$ molecule immobilized with PDA nanowire sometimes exhibits internal structures 
at RT as shown in inset of Figure 4A, strongly indicating that the rotational motion of the $\mathrm{C}_{60}$ molecule is inhibited owing to the covalent bonding similar to the $\mathrm{C}_{60}$ molecules cross-linked via [2+2] cycloadditive four-membered rings. ${ }^{30,32}$ These result strongly indicates that the $\mathrm{C}_{60}$ molecules diffusing on the surface have accidentally encountered and reacted with a propagating forefront part of PDA in which reactive chemical species (carbene or radical) appear. ${ }^{33}$ Figure $4 \mathrm{~B}$ is possible chemical reaction between the PDA and the $\mathrm{C}_{60}$ molecule, in which the carbene at the forefront part of PDA reacts to 6-6 part in the $\mathrm{C}_{60}$ molecule, resulting that the double bond of $\mathrm{C}_{60}$ molecule are cleaved and then three membered ring are formed via [1+2] cycloaddition reaction as a intermolecular bond. Although similar chemical reaction has been widely used in chemical synthesis of $\mathrm{C}_{60}$ derivatives achieved by covalently connecting various carbene species to $\mathrm{C}_{60}$ molecules,${ }^{34-37}$ the present result is the first demonstration for usage of this reaction in surface synthesis of huge molecular complexes.

It has been also found that at least the $\mathrm{C}_{60}$ frontier molecular orbitals are shifted in energy after reacting with the end of a PDA nanowire. Figure 5 shows height profiles of STM tip taken along lines intersecting an anchor $\mathrm{C}_{60}$ molecule in $\mathrm{C}_{60}$ island connected to PDA and the other molecules existing in the island, as shown by a dotted line in inset, for example. Blue and red curves are taken by imagings at filled $\left(V_{\mathrm{s}}<0\right)$ and empty $\left(V_{\mathrm{s}}>0\right)$ states of each $\mathrm{C}_{60}$-PDA junction formed on HOPG and $\mathrm{MoS}_{2}$ surfaces, respectively. In some of profiles, tip height is clearly measured higher on the anchor $\mathrm{C}_{60}$ molecule than that on the other $\mathrm{C}_{60}$ molecules in islands. This corresponds to the above mentioned result that the 
anchor $\mathrm{C}_{60}$ molecule exhibits brighter appearance than the others in STM images. Interestingly, the tip-height profiles over the anchor $\mathrm{C}_{60}$ molecule change depending on the value of bias voltages in both bias polarities, strongly indicating that the electronic structure of the anchor $\mathrm{C}_{60}$ molecule is modified. Although the highest occupied molecular orbital (HOMO) and the lowest unoccupied molecular orbital (LUMO) levels of pristine $\mathrm{C}_{60}$ molecules adsorbed on the chemically inert surfaces appear at $V_{\mathrm{s}}$ of -2.5 $\mathrm{V}$ and $+1.4 \mathrm{~V}$ in the STS mesurement, ${ }^{30}$ respectively, the tip-height difference becomes remarkable at the smaller bias region than them. This fact implies that the HOMO-LUMO gap of the anchor $\mathrm{C}_{60}$ molecule is smaller than that of the pristine $\mathrm{C}_{60}$ molecule. This consideration is qualitatively consistent with the preceding conclusion that the $\mathrm{C}_{60}$ molecule is covalently bond to the PDA nanowire, because it is known that the HOMO-LUMO gap of a $\mathrm{C}_{60}$ molecule decreases by covalent bonding with surfaces $^{38,39}$ or other molecular species, ${ }^{39}$ which originates from splitting of HOMO and/or LUMO levels owing to impairing the symmetrical molecular structure.

On the other hands, since the DA SAM behaves as a thin insulating layer between $\mathrm{C}_{60}$ molecules and conductive substrate, connecting the $\mathrm{C}_{60}$ molecule to conductive polymer would increase an electronic coupling between the $\mathrm{C}_{60}$ molecule and the substrate, which is another possible cause for the bright appearance of the $\mathrm{C}_{60}$ molecule in the $\mathrm{STM}$ imaging of $\mathrm{C}_{60}$-PDA junctions, similar to the case of lander molecules connecting at the step edge of metallic substrate. ${ }^{41,42}$ Toward best of our understanding about present results, further clarification about geometry and energy level alignment of 
$\mathrm{C}_{60}$-PDA nanojunction should be carried out by STS and theoretical studies, which also could provide us insights into electrical properties of the $\mathrm{C}_{60}$-PDA nanojunction such as the low voltage electronic conductance of this molecular junction, its current-voltage characteristics and the effective charge carrier injection barrier.

\section{CONCLUSIONS AND PROSPECTS}

To summarize, a nanoscale heterojunction composed of the $\mathrm{C}_{60}$ molecule and the PDA nanowire has been constructed on a solid surface. In this nanojunction, a single $\mathrm{C}_{60}$ molecule is covalently bound to the edge of $\pi$-conjugated PDA backbone. This covalent interaction is considered to reduce the HOMO-LUMO gap of the $\mathrm{C}_{60}$ molecule in $\mathrm{C}_{60}-\mathrm{PDA}$ nanojunction. This $\mathrm{C}_{60}$-PDA nanojunction has been novel considering the huge molecular complex created by only our chemical soldering experiments on a surface. Further clarification about geometry and electronic structures of the $\mathrm{C}_{60}-\mathrm{PDA}$ molecular junction would clarify the functionality of such the complex. Particularly, conduction and injection properties of electrons, holes or polarons among closely-connected two kinds of $\pi$-conjugated molecular systems, are attractive. Another attractive challenge is to actively control the formation and annihilation of the covalent bond between the $\mathrm{C}_{60}$ molecule and PDA nanowire, such as that realized between $\mathrm{C}_{60}$ molecules. ${ }^{30,31,43}$ The current results and these next challenges would lead to realization of a molecular nanoelectronics using the molecule-polymer nanojunctions. 


\section{EXPERIMENTAL METHODS}

Sample preparation: All experiments were carried out in an UHV chamber with a base pressure of $1.0 \times 10^{-8} \mathrm{~Pa}$. The DA SAM and $\mathrm{C}_{60}$ nanoislands were formed by simultaneously depositing DA compound and $\mathrm{C}_{60}$ molecules at RT, respectively, onto clean surfaces of $\mathrm{HOPG}$ and $\mathrm{MoS}_{2}$. The HOPG and $\mathrm{MoS}_{2}$ were cleaved in air followed by thermal annealing at $500^{\circ} \mathrm{C}$ in UHV. Deposition of DA and $\mathrm{C}_{60}$ molecules were carried out by the thermal evaporation of molecular powders with purity of above 97\% and 99.995\% from a Ta boat and BN crucible while maintaining a deposition rate of 0.1 and of $0.01 \mathrm{ML} / \mathrm{min}$, respectively. All the STM experiments were carried out using an electrochemically etched Pt-20\%Ir tip at RT.

Supporting Information Available: STM observation of a DA SAM after covering with $\mathrm{C}_{60}$ monolayer films. This material is available free of charge via the Internet at http://pubs.acs.org

\section{REFERENCES}

[1] Joachim, C.; Gimzewski, J. K.; Aviram, A. Electronics Using Hybrid-Molecular and Mono-Molecular Devices. Nature 2000, 408, 541-548. 
[2] Donhauser, Z. J.; Mantooth, B. A.; Kelly, K. F.; Bumm, L. A.; Monnell, J. D.; Stapleton, J. J.;

Price Jr., D. W.; Rawlett, A. M.; Allara, D. L.; Tour, J. M.; et al. Conductance Switching in Single Molecules Through Conformational Changes. Science, 2001, 292, 2303-2307.

[3] Tao, N. J. Electron Transport in Molecular Junctions. Nat. Nanotechnol. 2006, 1, 173-181.

[4] Song, H.; Reed, M. A.; Lee, T. Single Molecule Electronic Devices. Adv. Mater. 2011, 23, 1583-1608.

[5] Aviram, A.; Ratner, M. R. Molecular Rectifiers. Chem. Phys. Lett. 1974, 29, 277-283.

[6] Gao, H. J.; Sohlberg, K.; Xue, Z. Q.; Chen, H. Y.; Hou, S. M.; Ma, L. P.; Fang, X. W.; Pang, S. J.; Pennycook, S. J. Reversible, Nanometer-Scale Conductance Transitions in an Organic Complex. Phys. Rev. Lett. 2000, 84, 1780-1783.

[7] Pathem, B. K.; Claridge, S. A.; Zheng, Y. B.; Weiss, P. S. Molecular Switches and Motors on Surfaces. Annu. Rev. Phys. Chem. 2013, 64, 605-630.

[8] Yang, Y. -W.; Sun, Y. -L.; Song, N. Switchable Host-Guest Systems on Surfaces. Acc. Chem. Res, dx.doi.org/10.1021/ar500022f, in press.

[9] Imahori, H.; Tamaki, K.; Guldi, D. M.; Luo, C.; Fujitsuka, M.; Ito, O.; Sakata, Y.; Fukuzumi, S. Modulating Charge Separation and Charge Recombination Dynamics in Porphyrin-Fullerene Linked Dyads and Triads: Marcus-Normal versus Inverted Region. J. Am. Chem. Soc. 2001, 123, 2607-2617. 
[10] Witlicki, E. H.; Johnsen, C.; Hansen, S. W.; Silverstein, D. W.; Bottomley, V. J.; Jeppesen, J. O.;

Wong, E. W.; Jensen, L.; Flood, A. H. Molecular Logic Gates Using Surface-Enhanced Raman-Scattered Light. J. Am. Chem. Soc. 2011, 133, 7288-7291.

[11] Wada, Y.; Tsukada, M.; Fujihira, M.; Matsushige, K.; Ogawa, T.; Haga, M.; Tanaka, S. Prospects and Problems of Single Molecule Information Devices. Jpn. J. Appl. Phys. 2000, 39, 3835-3849.

[12] Okawa, Y.; Mandal, S. K.; Hu, C.; Tateyama, Y.; Goedecker, S.; Tsukamoto, S.; Hasegawa, T.; Gimzewski, J. K.; Aono, M. Chemical Wiring and Soldering toward All-Molecule Electronic Circuitry. J. Am. Chem. Soc. 2011, 133, 8227-8233.

[13] Umeyama, T.; Tezuka, N.; Kawashima, F.; Seki, S.; Matano, Y.; Nakao, Y.; Shishido, T.; Nishi, M.; Hirao, K.; Lehtivuori, H.; et al. Carbon Nanotube Wiring of Donor-Acceptor Nanograins by Self-Assembly and Efficient Charge Transport. Angew. Chem. 2011, 123, 4711-4715.

[14] Sakaguchi, H.; Matsumura, H.; Gong, H.; Abouelwafa, A. M. Direct Visualization of the Formation of Single-Molecule Conjugated Copolymers. Science 2005, 310, 1002-1006.

[15] Treier, M.; Richardson, N. V.; Fasel, R. Fabrication of Surface-Supported Low-Dimensional Polyimide Networks. J. Am. Chem. Soc. 2008, 130, 14054-14055.

[16] Cai, J.; Ruffieux, P.; Jaafar, R.; Bieri, M.; Braun, T.; Blankenburg, S.; Muoth, M.; Seitsonen, A. P.; Saleh, M.; Feng, X.; et al. Atomically Precise Bottom-Up Fabrication of Graphene Nanoribbons. Nature 2010, 466, 470-473. 
[17] Nakaya, M.; Aono, M.; Nakayama, T. Scanning Tunneling Microscopy and Spectroscopy of Electron-Irradiated Thin Films of $\mathrm{C}_{60}$ Molecules. Carbon 2011, 49, 1829-1833.

[18] Lafferentz, L.; Eberhardt, V.; Dri, C.; Africh, C.; Comelli, G.; Esch, F.; Hecht, S.; Grill, L. Controlling On-Surface Polymerization by Hierarchical and Substrate-Directed Growth. Nature Chem. 2012, 4, 215-220.

[19] Kroto, H. W.; Heath, J. R.; O'Brien, S. C.; Curl, R. F.; Smalley, R. E. C60: Buckminsterfullerene. Nature 1985, 318, 162-163.

[20] Okawa, Y.; Akai-Kasaya, M.; Kuwahara, Y.; Mandala, S. K.; Aono, M. Controlled Chain Polymerisation and Chemical Soldering for Single-Molecule Electronics. Nanoscale, 2012, 4, $3013-3028$.

[21] Giridharagopal, R.; Kelly, K. F. Substrate-Dependent Properties of Polydiacetylene Nanowires on Graphite and $\mathrm{MoS}_{2}$. ACS Nano, 2008, 2, 1571-1580.

[22] Okawa, Y.; Aono, M. Linear Chain Polymerization Initiated by a Scanning Tunneling Microscope Tip at Designated Positions. J. Chem. Phys. 2001, 115, 2317-2322.

[23] Mandal, S. K.; Okawa, Y.; Hasegawa, T.; Aono, M. Rate-Determining Factors in the Chain Polymerization of Molecules Initiated by Local Single-Molecule Excitation. ACS Nano, 2011, 5, 2779-2786. 
[24] Núñez-Regueiro, M.; Marques, L.; Hodeau, J -L.; Béthoux, O.; Perroux, M. Polymerized Fullerite Structures. Phys. Rev. Lett. 1995, 74, 278-281.

[25] Mena-Osteritz, E.; Bäuerle, P. Complexation of $\mathrm{C}_{60}$ on a Cyclothiophene Monolayer Template. Adv. Mater. 2006, 18, 447-451.

[26] Chen, L.; Chen, W.; Huang, H.; Zhang, H. L.; Yuhara, J.; Wee, A. T. S. Tunable Arrays of C60 Molecular Chains. Adv. Mater. 2008, 20, 484-488.

[27] Xu, B.; Tao, C.; Williams, E. D.; Reutt-Robey, J. E. Coverage Dependent Supramolecular Structures: C60:ACA Monolayers on Ag(111). J. Am. Chem. Soc. 2006, 128, 8493-8499.

[28] Bonifazi, D.; Kiebele, A.; Stöhr, M.; Cheng, F.; Jung, T.; Diederich, F.; Spillmann, H. Supramolecular Nanostructuring of Silver Surfaces via Self-Assembly of [60]Fullerene and Porphyrin Modules. Adv. Funct. Mater. 2007, 17, 1051.

[29] Wakayama, Y.; de Oteyza, D. G.; Garcia-Lastra, J. M.; Mowbray, D. J. Solid-State Reactions in Binary Molecular Assemblies of $\mathrm{F}_{16} \mathrm{CuPc}$ and Pentacene. ACS Nano, 2011, 5, 581-589.

[30] Nakaya, M.; Kuwahara, Y.; Aono, M.; Nakayama, T. Reversibility-Controlled Single Molecular Level Chemical Reaction in a $\mathrm{C}_{60}$ Monolayer via Ionization Induced by Scanning Tunneling Microscope. small 2008, 4, 538-541. 
[31] Akai-Kasaya, M.; Shimizu, K.; Watanabe, Y.; Saito, A.; Aono, M.; Kuwahara, Y. Electronic Structure of a Polydiacetylene Nanowire Fabricated on Highly Ordered Pyrolytic Graphite. Phys. Rev. Lett. 2003, 91, 255501.

[32] Nakaya, M.; Tsukamoto, S.; Kuwahara, Y.; Aono, M.; Nakayama, T. Molecular Scale Control of Unbound and Bound $\mathrm{C}_{60}$ for Topochemical Ultradense Data Storage in an Ultrathin $\mathrm{C}_{60}$ Film. $A d v$.

Mater. 2010, 22, 1622-1625.

[33] Neumann, W.; Sixl, H. The Mechanism of the Low Temperature Polymerization Reaction in Diacetylene Crystals. Chem. Phys. 1981, 58, 303-312.

[34] Win, W. W.; Kao, M.; Eiermann, M.; McNamara, J. J.; Wudl, F. Methyl 1,2-Dihydrofullerenecarboxylate. J. Org. Chem. 1994, 59, 5871-5876.

[35] Osterodt, J.; Vögtle, F. $\mathrm{C}_{61} \mathrm{Br}_{2}$ : A New Synthesis of Dibromomethanofullerene and Mass Spectrometric Evidence of the Carbon Allotropes $\mathrm{C}_{121}$ and $\mathrm{C}_{122}$. Chem. Commun., 1996, 547-548.

[36] Fabre, T. S.; Treleaven, W. D.; McCarley, T. D.; Newton, C. L.; Landry, R. M.; Saraiva, M. C.; Strongin, R. M. The Reaction of Buckminsterfullerene with Diazotetrazole. Synthesis, Isolation, and Characterization of $\left(\mathrm{C}_{60}\right)_{2} \mathrm{C}_{2} . J$. Org. Chem. 1998, 63, 3522-3523.

[37] Fernández, G.; Pérez, E. M.; Sánchez, L.; Martín, N. Self-Organization of Electroactive Materials: A Head-to-Tail Donor-Acceptor Supramolecular Polymer. Angew. Chem. Int. Ed. 2008, $47,1094-1097$. 
[38] Sakamoto, K.; Harada, M.; Kondo, D.; Kimura, A.; Kakizaki, A.; Suto, S. Bonding State of the C60 Molecule Adsorbed on a Si(111)-(7×7) Surface. Phys Rev B, 1998, 58,13951.

[39] Lu, X.; Grobis, M.; Khoo, K. H.; Louie, S. G.; Crommie, M. F. Charge Transfer and Screening in Individual $\mathrm{C}_{60}$ Molecules on Metal Substrates: A Scanning Tunneling Spectroscopy and Theoretical Study. Phys. Rev. B, 2004, 70, 115418.

[40] Wang, H.; He, Y.; Li, Y.; Su, H. Photophysical and Electronic Properties of Five PCBM-like C60 Derivatives: Spectral and Quantum Chemical View. J. Phys. Chem. A 2012, 116, 255-262.

[41] Stojkovic, S.; Joachim, C.; Grill, L.; Moresco, F. The Contact Conductance on a Molecular Wire. Chem. Phys. Lett. 2005, 408 134-138

[42] Moresco, F.; Gross, L.; Alemani, M.; Rieder, K.-H.; Tang, H.; Gourdon, A.; Joachim, C. Probing the Different Stages in Contacting a Single Molecular Wire. Phys. Rev. Lett. 2003, 91, 036601.

[43] Nakaya, M.; Aono, M.; Nakayama, T. Molecular-Scale Size Tuning of Covalently Bound Assembly of $\mathrm{C}_{60}$ Molecules. ACS Nano 2011, 5, 7830-7837. 


\section{Figure 1}

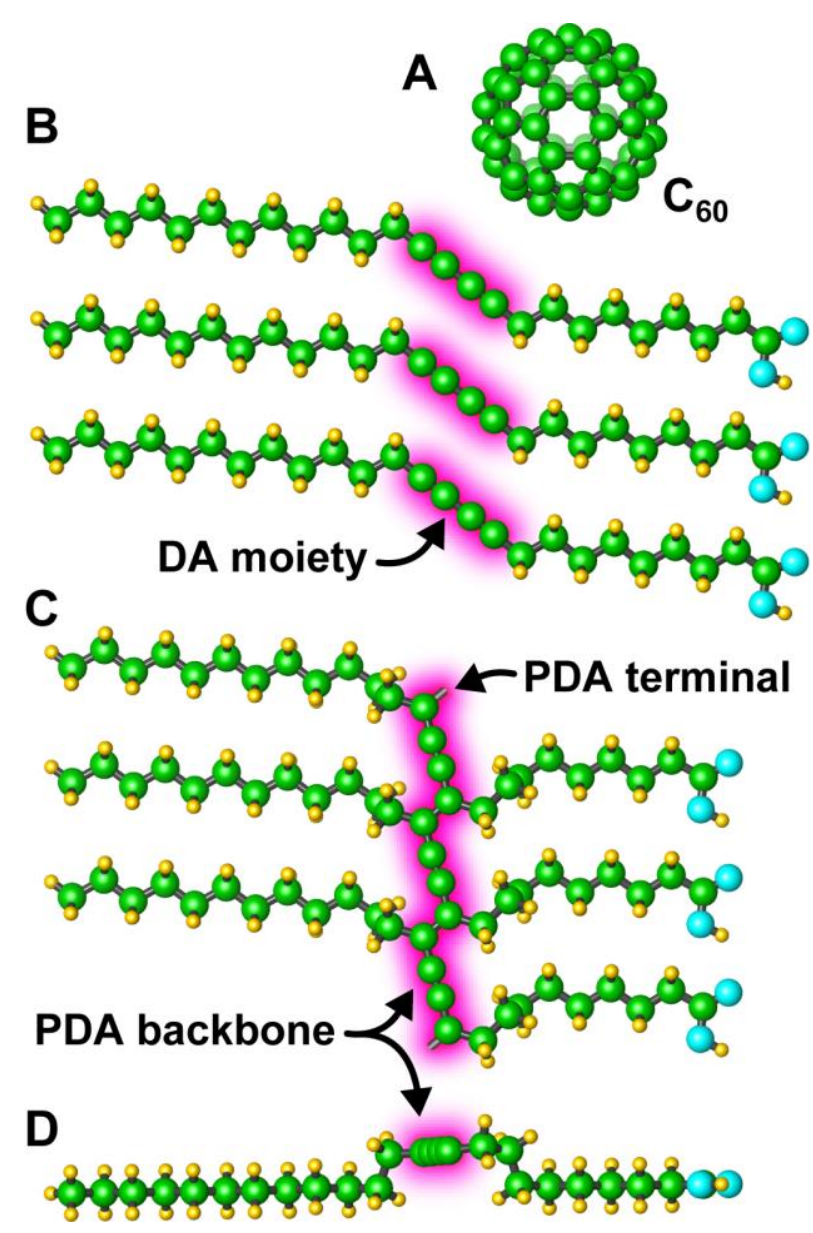

Figure 1. Molecular structure (Top view) of (A) $\mathrm{C}_{60}$, (B) monomers and (C) a polymer of 10,12-pentacosadiynoic acid. (D) is a side view of (C). Filled circles with colors of green, blue, and yellow correspond to carbon, oxygen, and hydrogen atoms, respectively. 


\section{Figure 2}
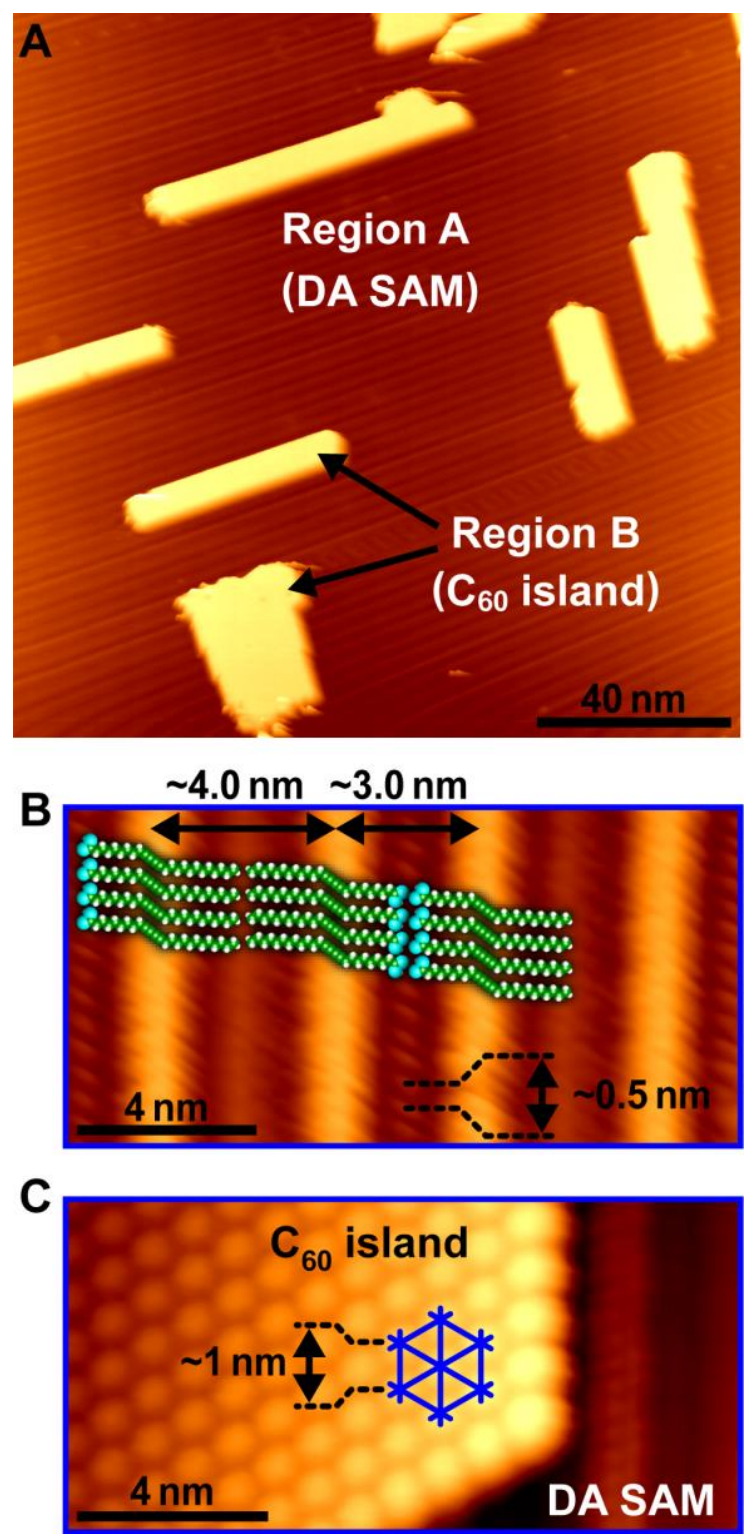

Figure 2. (A) Wide-scale STM image of $\mathrm{C}_{60}$ nanoislands and the DA SAM formed on the $\mathrm{MoS}_{2}$ surface. (B) and (C) High-resolution STM images taken on the DA SAM and the $\mathrm{C}_{60}$ nanoisland, respectively, which are formed on HOPG surfaces. Inset in the (B) is a model of molecular arrangement in the DA SAM. The imaging conditions ( $V_{\mathrm{s}}$ and $I_{\mathrm{t}}$ ) are $2 \mathrm{~V}$ and $25 \mathrm{pA}$ for $(\mathrm{A}),-2.1 \mathrm{~V}$ and $30 \mathrm{pA}$ for $(\mathrm{B})$, and $-2 \mathrm{~V}$ and $30 \mathrm{pA}$ for $(\mathrm{C})$. 


\section{Figure 3}

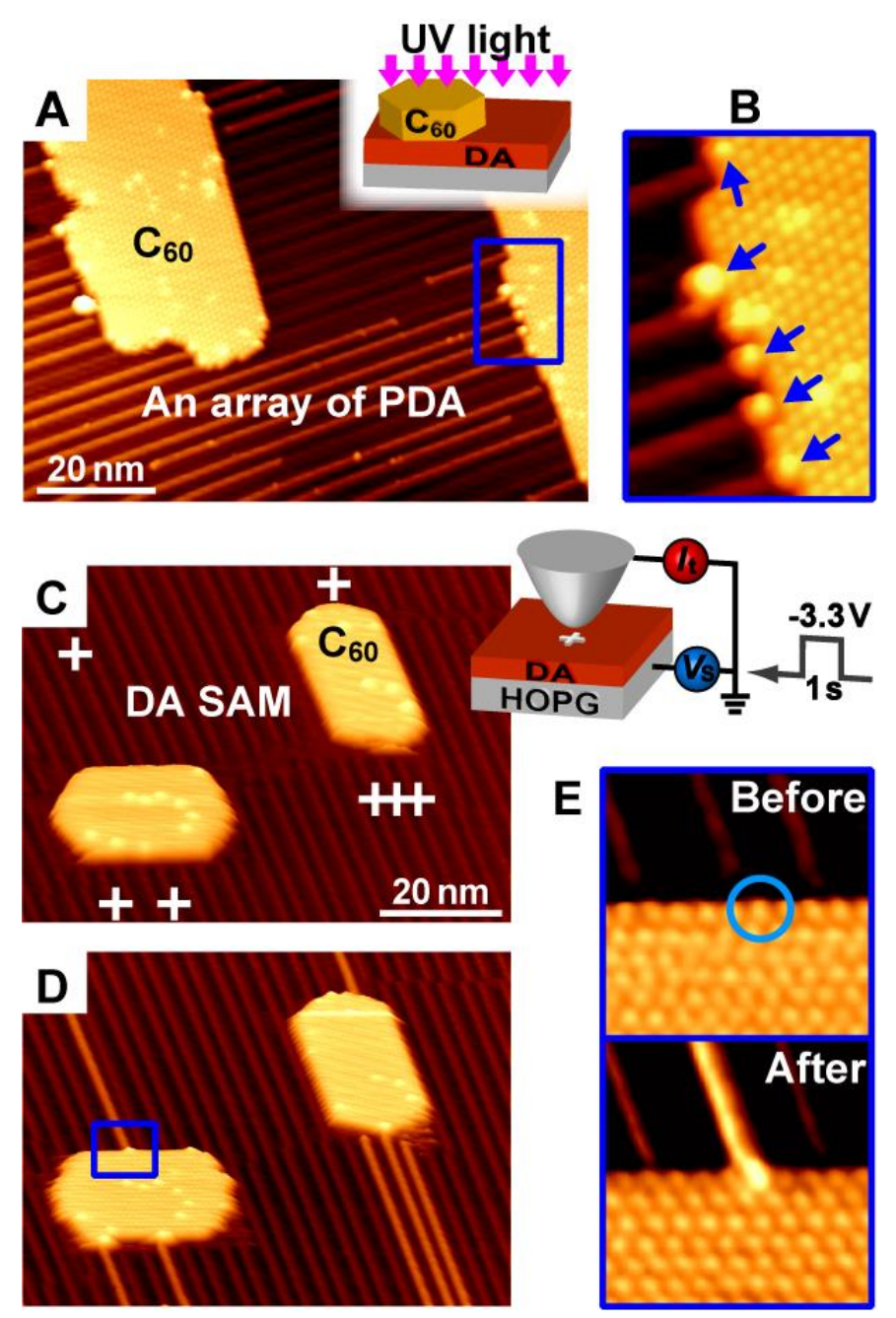

Figure 3. Creation of nanojunctions between $\mathrm{C}_{60}$ nanoislands and PDA nanowires. (A) Wide-scale STM image taken after inducing the chain polymerization by irradiating UV light for the overall region on the surface. (B) Magnified image of the region surrounded by a blue line in (A). (C) and (D) STM images taken before and after inducing chain polymerization by applying $V_{\mathrm{s}}$ of $-3.3 \mathrm{~V}$ at the positions indicated by crosses in (C) at for 1s, respectively. (E) Magnified image of the region surrounded by a blue line in (D). DA SAMs and $\mathrm{C}_{60}$ is lands were formed on HOPG surfaces. The imaging conditions $\left(V_{\mathrm{s}}\right.$ and $\left.I_{\mathrm{t}}\right)$ are $-2.2 \mathrm{~V}$ and $20 \mathrm{pA}$ for $(\mathrm{A})$ and $(\mathrm{B})$ and $-2 \mathrm{~V}$ and $30 \mathrm{pA}$ for $(\mathrm{C})-(\mathrm{E})$. 


\section{Figure 4}
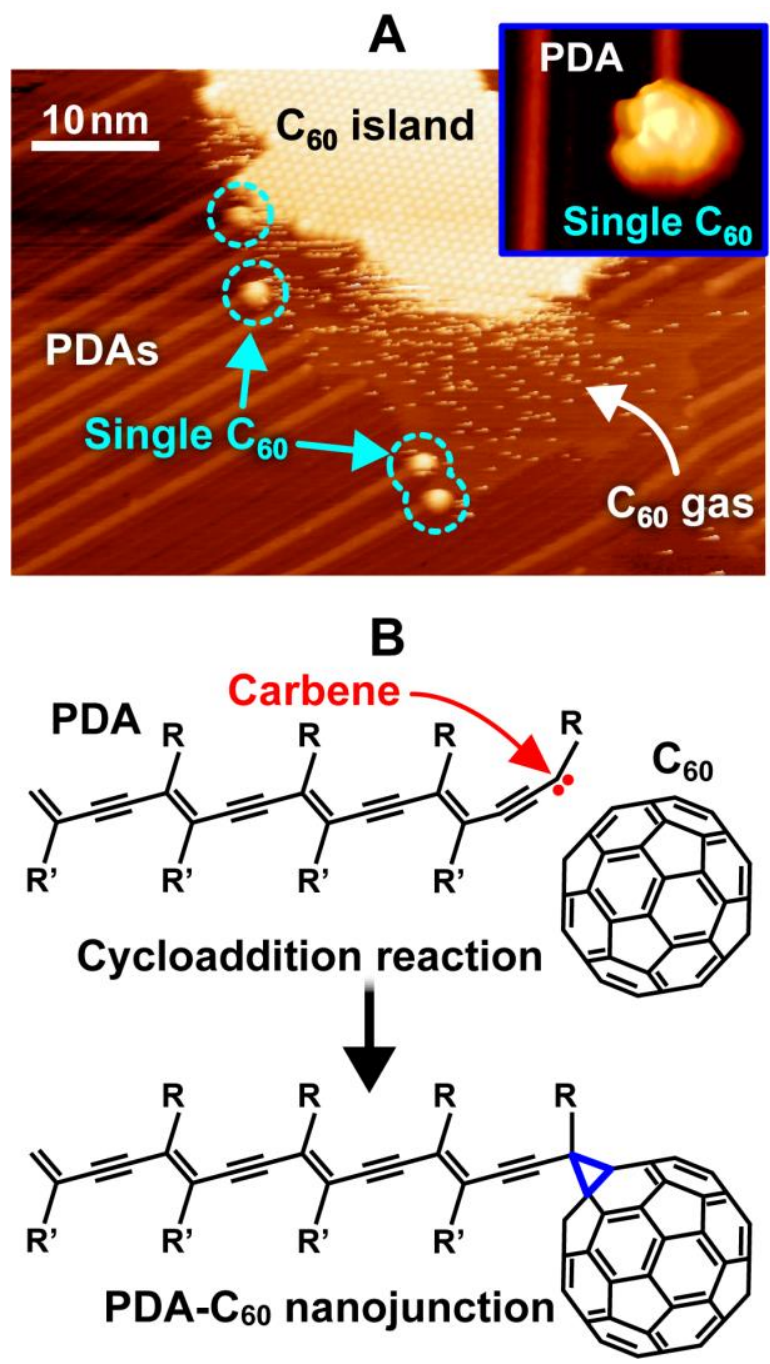

Figure 4. Covalent bonding between a single $\mathrm{C}_{60}$ molecule and an edge of PDA nanowire. (A) STM image of the nanoisland and 2D gas of $\mathrm{C}_{60}$ molecules on the DA SAM, which taken after inducing STM-inducing chain polymerization. The sample was formed on a HOPG surface. Inset in (A) is high resolution image of single $\mathrm{C}_{60}$ molecule connecting to PDA nanowire. The imaging conditions of (A) and its inset are $V_{\mathrm{s}}$ of $-2.3 \mathrm{~V}$ and $I_{\mathrm{t}}$ of $20 \mathrm{pA}$. (B) cycloaddition reaction between $\mathrm{C}_{60}$ molecules and PDA nanowire, which is possible candidates for the chemical reaction creating $\mathrm{C}_{60}$-PDA nanojunctions. 


\section{Figure 5}

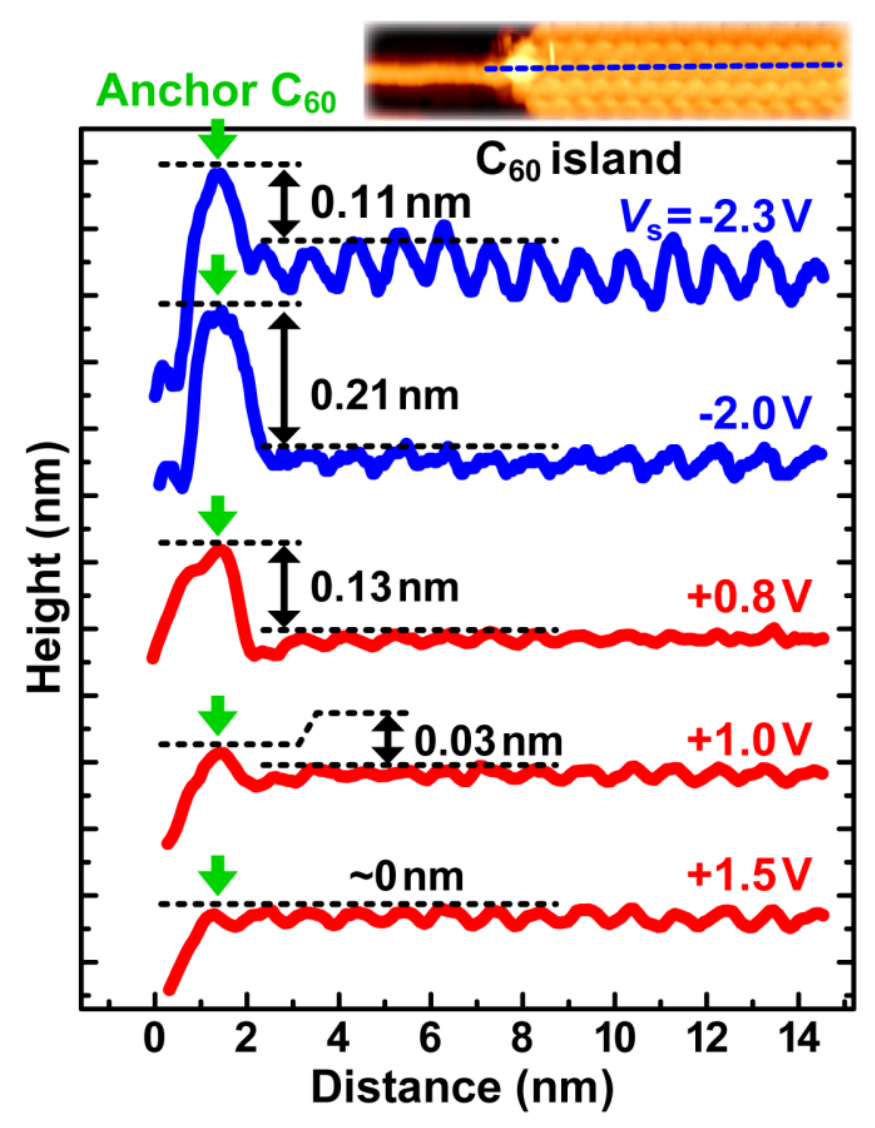

Figure 5. Modification of electronic DOS of $\mathrm{C}_{60}$ molecule connected with PDA nanowire. Cross sectional line profiles intersecting $\mathrm{C}_{60}$ molecule closely connecting PDA (each green arrow) and the others existing in $\mathrm{C}_{60}$ nanoisland, which taken at $V_{\mathrm{s}}$ of $-2.3,-2.0,0.8,1.0$, and $1.5 \mathrm{~V}$. Blue and red curves were taken along $\mathrm{C}_{60}$-PDA junctions formed on $\mathrm{HOPG}$ and $\mathrm{MoS}_{2}$ surfaces, respectively. 


\section{Table of Contents Graphic}

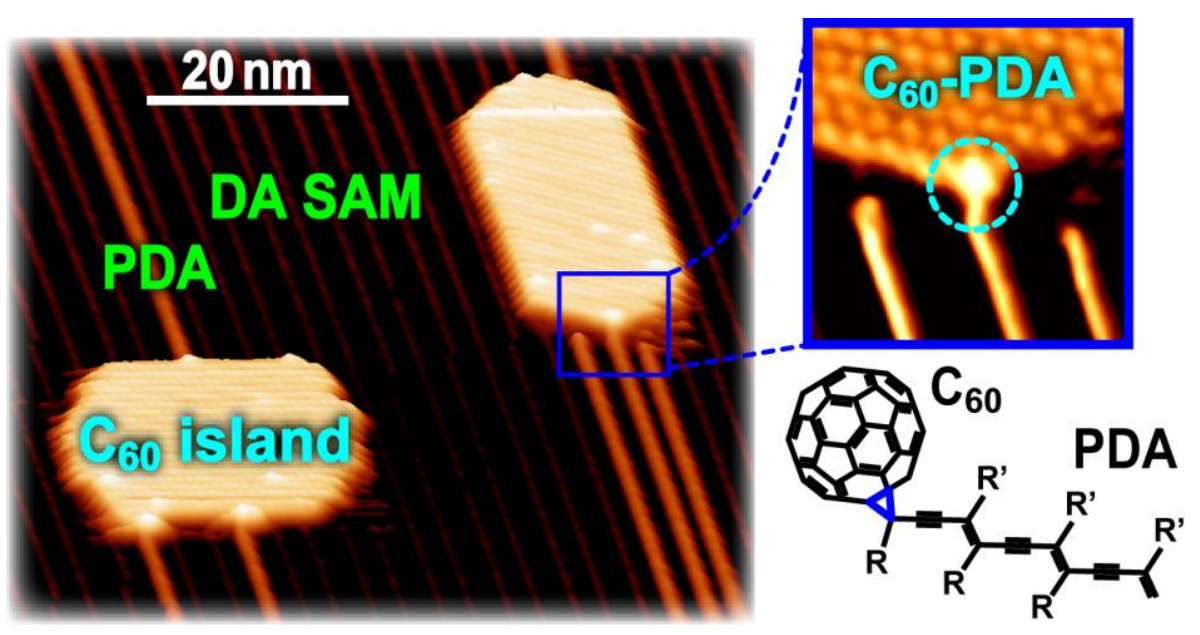

